\title{
Collagen-functionalised electrospun polymer fibers for bioengineering applications
}

\author{
Alessandro Polini, ${ }^{* a}$ Stefano Pagliara, ${ }^{a}$ Ripalta Stabile, ${ }^{a}$ Giuseppe Stefano Netti, ${ }^{b}$ Leonarda Roca, \\ Clelia Prattichizzo, ${ }^{b}$ Loreto Gesualdo, ${ }^{b}$ Roberto Cingolani ${ }^{a}$ and Dario Pisignano* ${ }^{* a}$
}

\author{
Received 21st October 2009, Accepted 10th December 2009 \\ First published as an Advance Article on the web 17th February 2010 \\ DOI: $10.1039 / b 921932 c$
}

\begin{abstract}
Polymer electrospun fibers are gaining increasing importance in nanobiotechnology, due to their intrinsic three-dimensional topography and biochemical flexibility. Here we present an in-depth study of protein functionalisation for polymethylmethacrylate fibers. We compare different coating approaches for type I collagen, including physisorption and covalent binding methods relying on functional linkers. The biofunctionalised fibers are investigated by scanning electron and confocal laser scanning microscopy, wettability measurements, Fourier-transform infrared spectroscopy, and protein quantification assays. We demonstrate that the largest amount of proteins adsorbed on fibers does not determine the best performance in terms of cell attachment and proliferation in vitro, which is instead related to the type of linking and the relevant role played by adsorption of serum biomolecules on the three-dimensional nanostructures. This study is relevant for designing and engineering novel biomaterials and scaffold architectures based on electrospun nanofibers.
\end{abstract}

\section{Introduction}

The possibility of controlling the surface topography and functionality of nanostructured materials is leading to applications in many fields, ${ }^{1,2}$ such as tissue engineered scaffolds, ${ }^{3}$ protein nanoarrays ${ }^{4}$ and biocatalysis platforms. ${ }^{5}$ A relevant issue for realising improved biomaterials is the immobilisation of biological molecules, such as proteins and DNA, providing specific functionalities to target surfaces. Indeed, it is well-known that the physiological properties of the extracellular matrix (ECM) are strongly dependent on its morphology and biochemical composition. ${ }^{6}$ In the case of polymeric nanostructures, different immobilisation approaches can be utilised for promoting protein adhesion, depending on the specific chemical composition of the polymer backbone and side-groups. Due to the intrinsic difficulty of functionalising organic surfaces which are amorphous at micro-scale, the full exploitation of the functionality of such nanostructures requires the in-depth characterisation of the resulting surface features, and the assessment of the actual potential in terms of cell adhesion and viability achievable by protein coatings.

In this framework, polymeric electrospun nanofibers can be employed to build three-dimensional (3D) environments, very advantageous by virtue of their ultra-high surface to volume ratio. $^{7}$ These can be important building blocks for bioengineering applications since, while pure ECM nanofibers tend to dissolve in aqueous conditions, ${ }^{\mathbf{8} 9}$ polymer, possibly insoluble, fibers coated by ECM proteins may both enhance human cell attachment and

${ }^{a} N N L$, National Nanotechnology Laboratory of INFM-CNR, Unità di Ricerca IIT, Istituto Superiore Universitario di Formazione Interdisciplinare (ISUFI), Università del Salento, Lecce, Italy. E-mail: alessandro.polini@unisalento.it; dario.pisignano@unisalento.it

${ }^{b}$ Department of Biomedical Sciences and BioAgroMed, University of Foggia, Foggia, Italy simultaneously preserve their 3D structure. ${ }^{10,11} \mathrm{He}$ et al. produce collagen-coated poly(L-lactic acid)-co-poly( $\varepsilon$-caprolactone) nanofiber nets and demonstrate an increment of the growth, viability and attachment of human coronary artery endothelial cells, preserving their specific phenotype. ${ }^{12}$ Choi and Yoo report on the gradual release of fluorescent proteins by surface-modified nanofibers. ${ }^{13}$ Kim and Park fabricate lysozyme-immobilized block co-polymeric nanofibers, showing how the enhanced exposed surface promotes catalytic activity in comparison to cast films. ${ }^{14}$ Very few works report on the morphology of electrospun polymer nanofibers upon protein-based surface modification, comparing different functionalisation methods. ${ }^{15,16}$

The morphology and effects of protein coatings on polymer nanofibers can be especially critical to some clinical applications. For instance, we point out that nowadays, the rising number of patients with acute and chronic renal failure worldwide creates urgency to search out alternative therapies other than chronic renal dialysis and/or organ transplantation. The development of ECM-protein functionalised nanofibrous scaffolds may represent in future a promising tool to address this issue. These nanostructured scaffolds might be able to induce stem cell adhesion, proliferation and differentiation in several renal cell types, providing a useful tool for organ regeneration both in vitro and in vivo. Focusing on the clinical setting, there are some unsolved issues which might benefit from this technology. In particular, the treatment of severe acute kidney injury (AKI) with dialysis or hemofiltration remains suboptimal with high levels of morbidity and mortality. Current renal replacement therapies substitute for the small solute clearance function of the kidney but do not replace the lost reclamation, metabolic and endocrine functions of this organ. Cell therapy and tissue engineering offer hope of fuller replacement of kidney function in renal failure patients and might really improve the treatment of this life-threatening pathology. ${ }^{17}$ A possible track may be the 
assembly of an extra-corporeal renal tubule assist device (RAD). This device might include a conventional hemodialysis filter and a bioreactor containing living renal proximal tubule cells. Recent data from phase I/II and phase II clinical studies show that the addition of renal tubule cell therapy to conventional continuous renal replacement therapy treatment resulted in a significant clinical impact on survival, and that RAD treatment demonstrates an acceptable safety profile. ${ }^{18}$ Another substantive advance for the treatment of AKI might be gained by the development of nanofabrication technology in the attempt to deliver in vivo exogenous stem cells into the injured kidney and to regenerate de novo the renal tissue with similar physiologic functions as native tissue. The development of ECM-protein functionalised nanofibrous scaffolds may be essential in this process.

In this paper, we present an exhaustive study of polymethylmethacrylate (PMMA) electrospun fibers functionalised with collagen. PMMA has several applications in different fields. ${ }^{19-22}$ In tissue engineering, various PMMA products are Food and Drug Administration approved orthopedic implants, used as bone cement since 1950s. Consequently, the promotion of PMMA scaffolds from experimental research to clinical use is relatively easy. ${ }^{23}$ Though this material is structurally very stable ${ }^{19,21,22}$ and widely investigated as surface to link biomolecules, ${ }^{24,25}$ electrospun PMMA fibers functionalised by ECM proteins are largely unexplored.

We realise fibers with well-controlled diameters, fully compatible with non-biodegradable tissue engineering requirements, ${ }^{26}$ and investigate several different functionalisation approaches. Human kidney 2 (HK-2), a well-known immortalised proximal tubular epithelial line, ${ }^{27}$ is used to analyse the adhesion and proliferation of renal cells. The adhesion of serum proteins on fibers is also studied to assess the overall biocompatibility of the material. We find that the largest amount of adsorbed ECM proteins, which is up to about $23 \mu \mathrm{g}$ of collagen per $\mathrm{mg}$ of fiber material, does not provide the best performance in terms of cell proliferation. This is instead mostly related to the type of physico-chemical protein binding, and optimised by zerolength linkers, retaining the best biofunctionality of the coated nanostructure. These results, possibly generalised to different polymer systems, are relevant for designing novel biomaterials based on electrospun nanofibers.

\section{Results and discussion}

We test chloroform, 1,2-dichloroethane (DCE), and formic acid as electrospinning solvents to obtain PMMA fibers with good diameter uniformity and mat size. Because of the low boiling point $\left(62-100{ }^{\circ} \mathrm{C}\right)$, these solvents exhibit a high evaporation rate, further enhanced by the large air-exposed area of the electrospinning jet and resulting fibers. ${ }^{28}$ Toxic solvent residuals are therefore generally considered insignificant for tissue engineering. ${ }^{29,30}$ Upon fixing the solution concentration $(16 \% \mathrm{w} / \mathrm{w})$ and processing parameters (injection rate $10 \mu \mathrm{min}^{-1}$, electrospinning bias $9 \mathrm{kV}$, needle-collector distance $9 \mathrm{~cm}$ ), the best fibers are obtained by formic acid (Fig. 1a-c), i.e. by means of the solvent with highest dielectric constant. ${ }^{31}$ The resulting fibers are well defined, exhibit uniform sub- $\mu \mathrm{m}$ diameter and a very low amount of beads (Fig. 1c). Secondly, we investigate the effect of
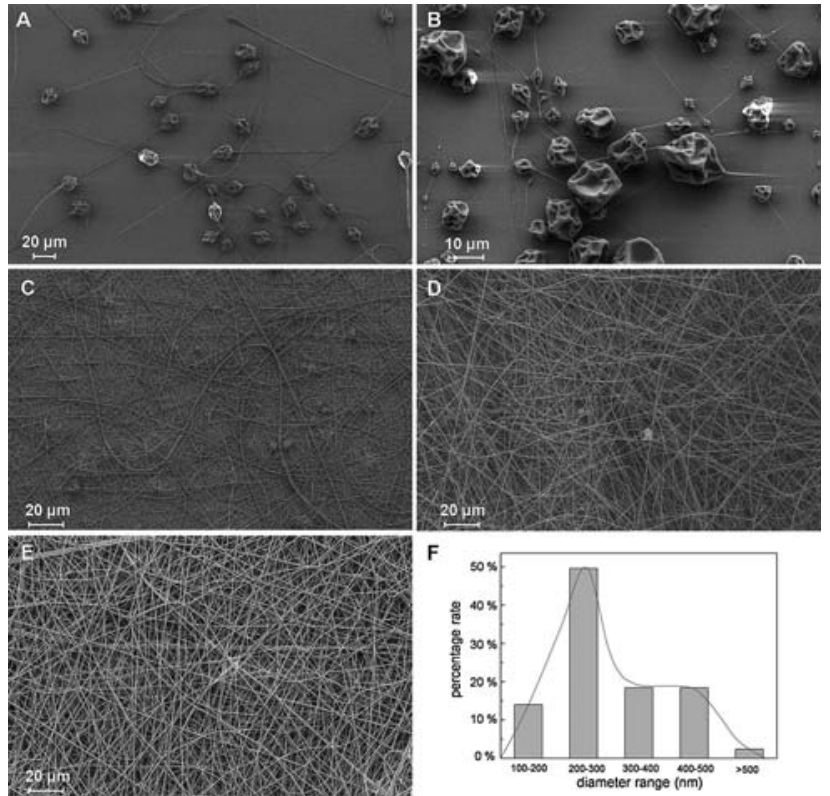

Fig. 1 SEM micrographs of PMMA nanofibers electrospun from different solutions: $16 \% \mathrm{w} / \mathrm{w}$ in chloroform (a), $16 \% \mathrm{w} / \mathrm{w}$ in DCE (b), (c-e): $16 \%, 21 \%$ and $26 \% \mathrm{w} / \mathrm{w}$ in formic acid. (f) Relative nanofibers frequency (\%) for each diameter range, as produced from a $26 \% \mathrm{w} / \mathrm{w}$ formic acid solution. More than $96 \%$ of the nanofibers have diameter below $500 \mathrm{~nm}$. The continuous line is a guide for the eye.

the solution concentration on the fiber diameter, preparing different formic acid solutions with PMMA amount in the range $16-30 \%$ (Fig. 1c-e). We find that polymer concentrations below $26 \%$ generally cause the presence of beads, whereas at higher concentrations the solution is too viscous and unsuitable to be electrospun. The optimal concentration $(26 \%)$ results in fibers with an average diameter of $300 \mathrm{~nm}$, the most of which $(>95 \%)$ exhibit a diameter in the $100-500 \mathrm{~nm}$ range (Fig. 1f), namely comparable to the typical size of ECM nanoarchitectures. ${ }^{32}$

Before biofunctionalisation, fibers are treated by oxygen plasma, increasing the surface oxygen content, ${ }^{33}$ introducing carboxylates and greatly enhancing the water wettability of mats. ${ }^{34,35}$ While PMMA films show a hydrophilic behavior (water static contact angle on the surface, $\Theta=70^{\circ} \pm 1^{\circ}$ ), polymeric electrospun mats exhibit remarkable hydrophobicity $\left(\Theta=131^{\circ} \pm 1^{\circ}\right)$ because of the much higher surface roughness at the nanoscale. Upon plasma treatment, the mats exhibit a significant increase of hydrophilicity and a zero apparent water contact angle, thus being suitable to bind collagen with different methods (Fig. 2). Physical adsorption (PHY) is straightforward and widely employed to immobilise proteins on surfaces. ${ }^{36,37}$ Though aspecific, it generally preserves the native configuration of biomolecules. ${ }^{38}$ In a second approach, glutaraldehyde (GA) is added in a low concentration $(2 \%)$ to the collagen solution. In this way, both collagen and GA molecules are physically adsorbed on the target polymeric surface. Exploiting the GA crosslinking properties, in-solution collagen molecules are linked to previously adsorbed collagen. In fact, GA may easily react by several routes to form covalent crosslinks with amine-containing molecules. $^{39}$ In further methods, ethyl dimethylaminopropylcarbodiimide hydrochloride (EDC) is used as zero-length 

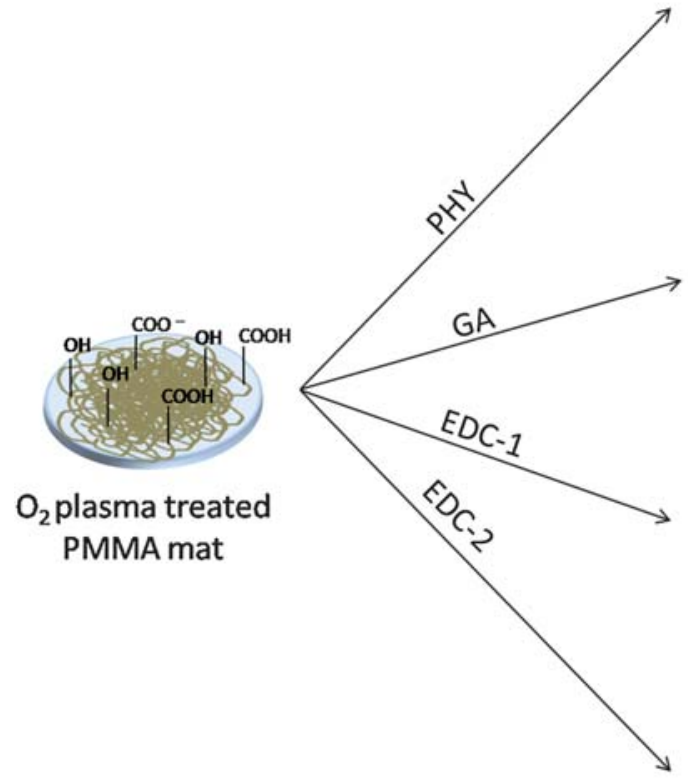
PMMA mat
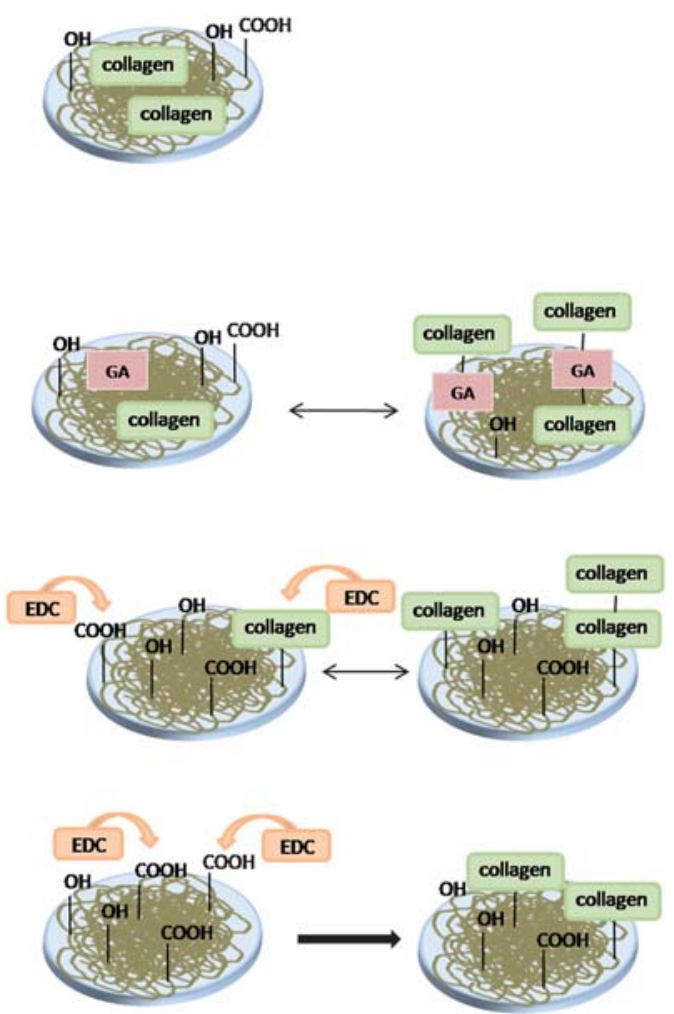

Fig. 2 Schematic of investigated surface modifications of PMMA nanofibers by collagen.

linking molecule, leaving in principle no residue on newly grafted structures, and binding proteins covalently without protein functionality failure. ${ }^{11,40} \mathrm{EDC}$ mediates the formation of amide linkages between carboxylates and amines. ${ }^{10,11,39,40}$ In a one step approach (EDC-1), the samples are incubated in a solution containing EDC molecules and collagen. Hence EDC may link collagen molecules both to plasma-treated fibers and to previously immobilised collagen. Finally, in a EDC two-step approach (EDC-2), in a first incubation EDC reacts with PMMA creating highly reactive $o$-acylisourea intermediates. These active species may then react with a nucleophile, such as a primary amine on collagen molecules, to form an amide bond during a second incubation.

The presence of adsorbed collagen and the resulting composition of fibers are first evaluated by horizontal attenuated total reflectance-Fourier transform infrared (HATR-FTIR) spectroscopy (Fig. 3). In general, all the investigated protein immobilisation approaches preserve the characteristic polymeric backbone. The spectra of as-produced, plasma-treated and collagen-coated fibers all present typical characteristics of PMMA ${ }^{41}$ namely a sharp peak at $1728 \mathrm{~cm}^{-1}$ due to ester carbonyl group stretching vibration, transitions in the $1260-1000 \mathrm{~cm}^{-1}$ range due to $\mathrm{C}-\mathrm{O}$ stretching, and peaks at $1475-1435 \mathrm{~cm}^{-1}$, and $1380-1375 \mathrm{~cm}^{-1}$ due to methyl stretching. On the contrary, stretching transitions at about 1650 and $1560 \mathrm{~cm}^{-1}$, characteristic of amide I and amide II, respectively, are observed only in collagen-coated fibers, due to the vibrations of the peptide carbonyl group. ${ }^{42}$

The 3D structure of fibers is also well preserved after plasma treatment and functionalisation, as inspected by scanning electron microscopy (SEM, Fig. 4). Furthermore, protein layers are clearly noticeable on functionalised fibers, with collagen forming well defined crosslinked membranes connecting neighbor fibers. Though such membranes may hinder the underlying nanofibrous topography, these collagen layers likely collapse on the fiber scaffold when placing the samples in cell medium. Indeed, by using fluorescein isothiocyanate (FITC)

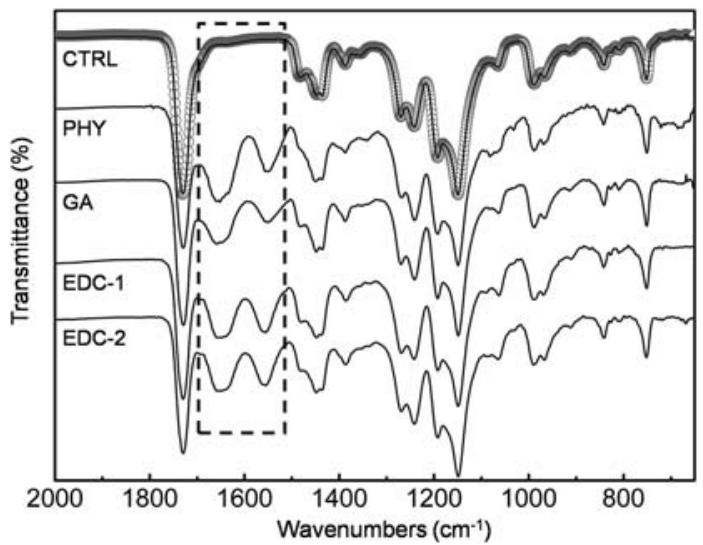

Fig. 3 HATR-FTIR spectra of PMMA electrospun nanofibers. From top to bottom: spectrum from as-produced (circles line of CTRL), treated by plasma (continuous line in CTRL), physisorption (PHY), GA-based (GA), EDC-1 step (EDC-1) and EDC-2 steps methods (EDC-2). The rectangle evidences the characteristic amide $\mathrm{I}\left(\approx 1650 \mathrm{~cm}^{-1}\right)$ and amide II $\left(\approx 1560 \mathrm{~cm}^{-1}\right)$ peaks, clearly present only in collagen-coated nanofibers. The signal from the PMMA backbone is unaltered in all the samples. 


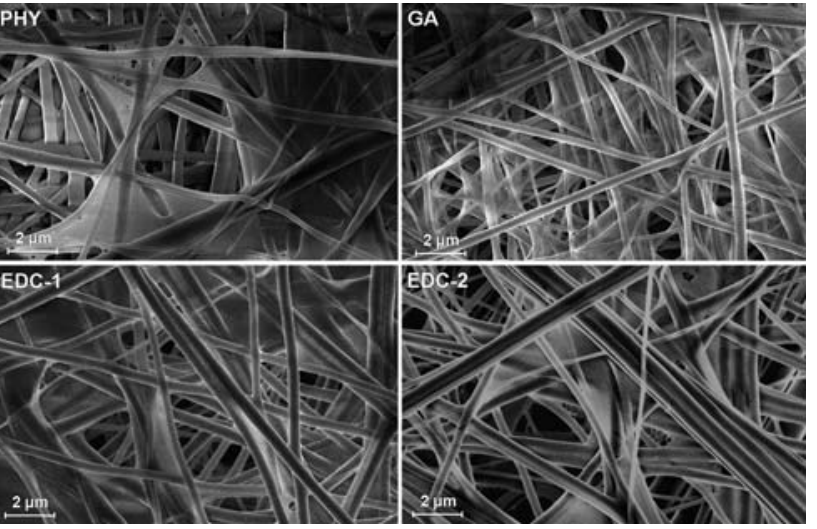

Fig. 4 SEM micrographs of PMMA fibers functionalised by PHY, GA, EDC-1 and EDC-2 approaches.

labelled collagen and confocal laser scanning microscopy (CLSM), a uniform distribution of collagen on fibers mats is clearly evidenced (Fig. 5).

In order to investigate the protein content on the fibrous scaffolds in liquid environments more in depth, a quantitative evaluation of the immobilised collagen is performed by a bicinchoninic acid (BCA) assay. ${ }^{43}$ As displayed in Fig. 6, PHY, GA, EDC-1, and EDC-2 binding methods allow one to coat $1 \mathrm{mg}$ of fibers with (14.5 \pm 2.4$),(23.1 \pm 2.5),(17.7 \pm 1.7)$, and $(17.2 \pm 2.0)$ $\mu \mathrm{g}$ of collagen, respectively. This confirms the general suitability of GA for obtaining large amounts of immobilised proteins, but does not necessarily provide an indication of the best scaffolds in terms of cell growth.

The protein binding methods can strongly affect the resulting biocompatibility of polymer nanofibers. In general, we observe that, after an initial stabilisation time of a few hours needed for adhesion (Fig. 7), the HK-2 cells exhibit a regular growth, and a cobblestone morphology at confluence. In fact, these are anchorage-dependent cells that usually assume a round morphology soon after trypsinisation, then stretching out on the surface only upon interacting with substrates suitable for their growth. By optical imaging, the scaffolds obtained by the different methods seem to have no significant differences in adhered cells number and morphology. However, the proliferation of cells on fibers is better quantified by a tetrazolium salt

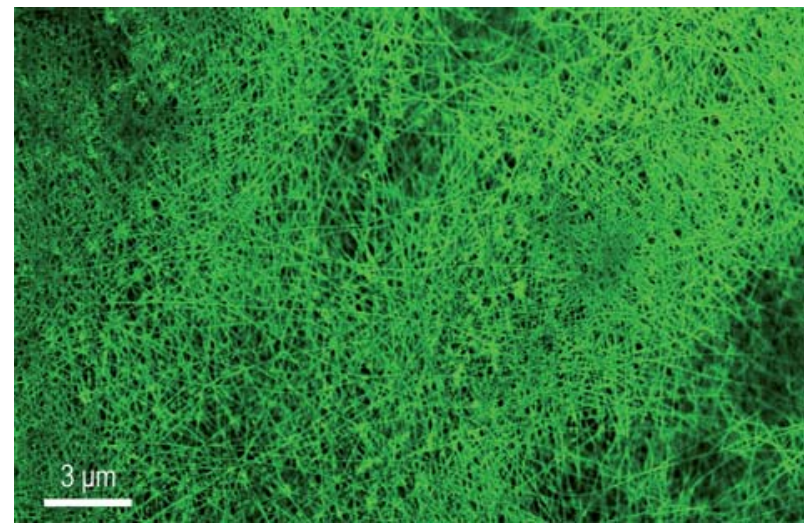

Fig. 5 CLSM micrograph of fibers functionalised by FITC-labeled collagen. Sample realized by PHY. Similar micrographs are obtained by all the investigated methods of functionalisation.

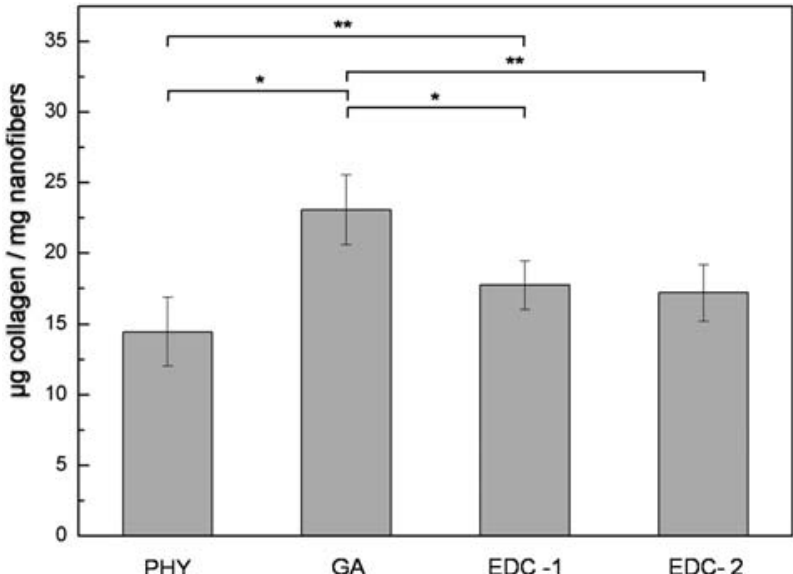

Fig. 6 Quantitative evaluation of protein coating by BCA assay. The vertical bars show standard deviations. *: $\mathrm{P}<0.01$; **: $\mathrm{P}<0.05$.

(MTS) assay, evidencing that, while the cell proliferation rate is initially analogous in protein-coated and uncoated samples under same culture conditions, some differences arise at a later stage (Fig. 8). As-produced and plasma-treated samples show a significantly lower cells proliferation rate with respect to protein-coated fibers. The EDC-2 method results in the most relevant cell proliferation, a quite slower growth is found on fibers treated by GA, the other samples showing instead an almost ceased residual cellular proliferation. These results also suggest that the PHY method, leading to a cell proliferation comparable to that of untreated scaffolds, likely binds weakly collagen, which is then rapidly degraded in the culture medium.

In addition, the serum proteins might play a key role for the cell proliferation, adhering unspecifically on the fibers and enabling the growth of cells even on initially hydrophobic substrates. To get an insight into this issue, we determine the degree of adhesion of serum proteins on fibers during the cell harvesting times by a total protein quantification by BCA (Table 1) The collagen-functionalised samples exhibit an increase of total adsorbed proteins, up to two times the initial amount of collagen. Moreover, we note that serum proteins rapidly adhere also on control samples, namely as-produced and plasma-treated fiber mats. The amount of proteins adsorbed on controls roughly saturates around the values adhered on the first day, in the range of $8-10 \mu \mathrm{g}$ per $\mathrm{mg}$ of fibers. This result confirms the importance of the 3D nanostructure, able to immobilise serum proteins, ${ }^{44}$ which can be usefully exploited for enhancing the biocompatibility and the subsequent cell proliferation.

Overall, these findings evidence the lack of direct correspondence between the initial amount of surface-linked ECM proteins and the resulting cell growth, which is important for designing nanostructured biomaterials and functionalisation recipes. Even taking into account the intrinsic property of 3D nanostructured scaffolds to immobilise biomolecules from the culture serum, a stable biofunctionalisation by ECM proteins is critical to yield the utmost cell proliferation.

\section{Conclusions}

PMMA fibers are fabricated by electrospinning with diameters in the range $100-500 \mathrm{~nm}$, which are ideal for tissue engineering 

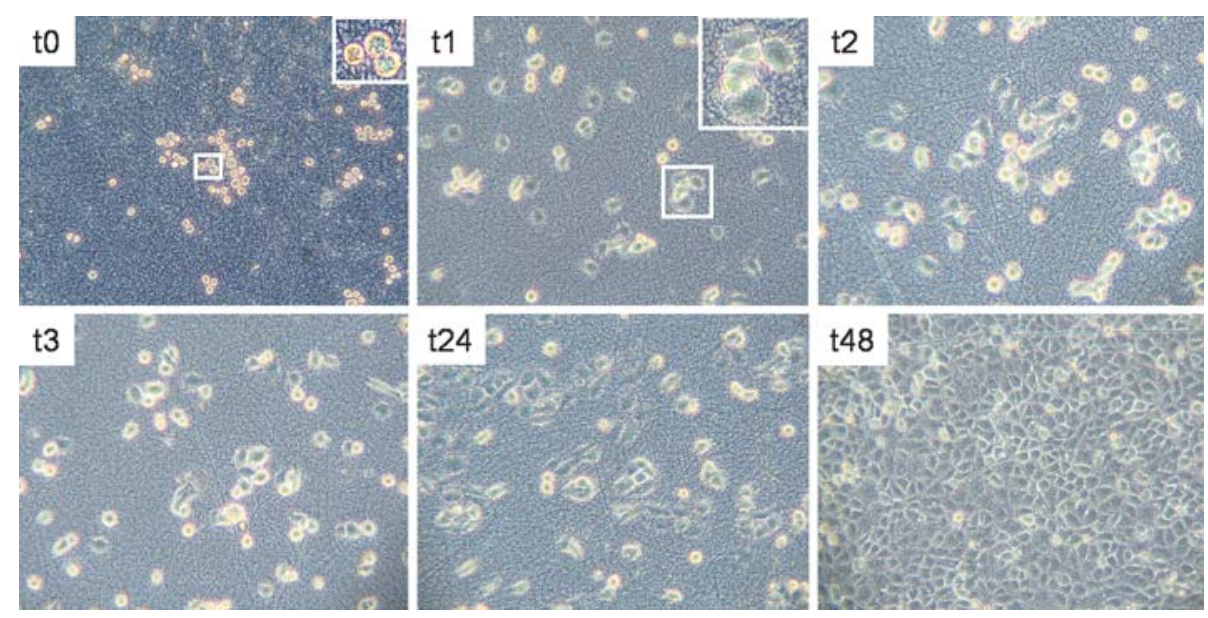

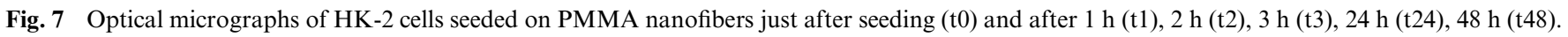
Proteins adsorbed by PHY.

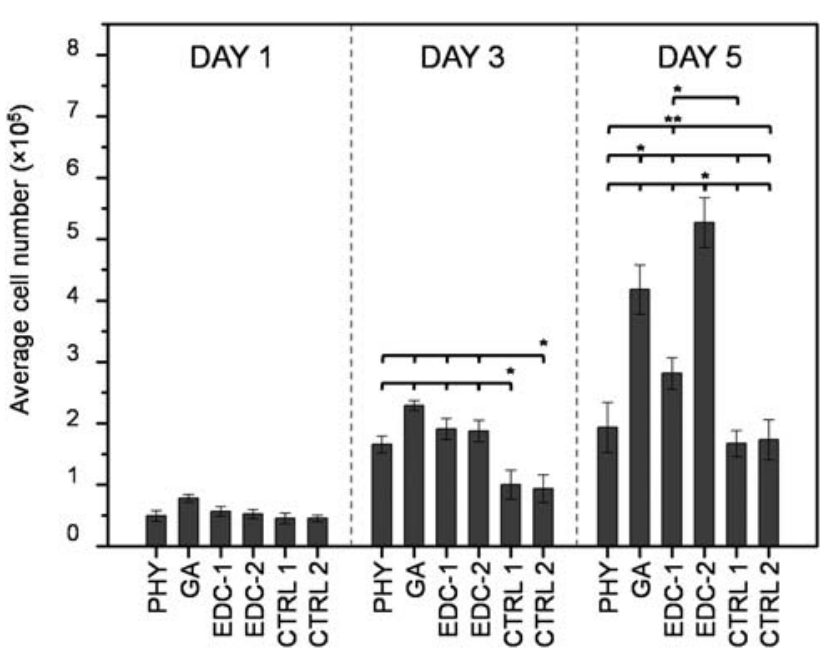

Fig. 8 Number of cells proliferated on collagen-functionalised PMMA nanofibers processed by PHY, GA, EDC-1, and EDC-2 approaches, and on as-produced (CTRL 1) and plasma-treated (CTRL 2) fibers. Initial seeding $=4 \times 10^{4}$ cells $\mathrm{ml}^{-1}$. The vertical bars show standard deviations. $*: \mathrm{P}<0.01 ; * *: \mathrm{P}<0.05$.

Table 1 Total adsorbed proteins by BCA. Values normalised to the amount measured initially for collagen for functionalised samples, and to the amount of serum protein adsorbed at day 1 for control samples [ 8.9 $\pm 1.2) \mu \mathrm{g}$ and $(10.9 \pm 2.5) \mu \mathrm{g}$ per $\mathrm{mg}$ of nanofiber materials for asproduced and plasma-treated samples, respectively]

\begin{tabular}{lllll}
\hline Method & Day 0 & Day 1 & Day 3 & Day 5 \\
\hline PHY & 1 & $2.4( \pm 0.5)$ & $2.5( \pm 0.5)$ & $2.5( \pm 0.4)$ \\
GA & 1 & $1.2( \pm 0.2)$ & $1.3( \pm 0.3)$ & $0.9( \pm 0.1)$ \\
EDC-1 & 1 & $2.1( \pm 0.7)$ & $2.1( \pm 0.8)$ & $1.8( \pm 0.5)$ \\
EDC-2 & 1 & $2.2( \pm 1.1)$ & $2.3( \pm 1.2)$ & $2.1( \pm 1.2)$ \\
CTRL 1 & - & 1 & $1.0( \pm 0.3)$ & $0.9( \pm 0.2)$ \\
CTRL 2 & - & 1 & $0.9( \pm 0.4)$ & $0.8( \pm 0.2)$ \\
\hline
\end{tabular}

applications. $^{32}$ Morphological, spectroscopic and chemical analyses indicate that GA allows us to achieve the highest amount of initially adsorbed proteins, but the EDC-2 coating better promotes the growth of HK-2. These findings evidence the role of functionalisation on the resulting cellular behavior on nanostructured scaffolds, highlighting a lack of direct correlation between amount of surface-linked ECM proteins and cell proliferation, and the relevant role of serum proteins adsorbed onto 3D polymer nanostructures.

The advantages of ECM protein coating of nanofibrous scaffolds are numerous, including the reduction of proteic material waste with respect protein blending in the electrospinning solution, and the stability of polymeric structure in water. ${ }^{19,20}$ These results are relevant for bioengineering novel biomaterials and $3 \mathrm{D}$ scaffold architectures based on electrospun polymer fibers.

\section{Experimental}

\section{Materials}

PMMA (M.W. $120 \mathrm{kDa}$ ), collagen type I from calf skin powder, FITC labeled type I collagen, acetic acid, EDC, Grade I 50\% GA solution, BCA kit, Dulbecco's Modified Eagle's Medium Mixture F-12 Ham (DMEM/F12), 0.05\% trypsin/0.2\% ethylenediaminetetraacetic acid (EDTA) solution, and organic solvents are purchased from Sigma-Aldrich. Au granulate is from Umicore Materials AG. HK2 cells are from ATCC. Fetal bovine serum (FBS), phosphate buffered saline (PBS) and 100X Penicilline - Streptomycine solution are from Euroclone. CellTiter 96 AQueous One Solution Cell Proliferation Assay (MTS) is from Promega.

\section{Fabrication of fibers}

For electrospinning, the PMMA powder is dissolved in different solvents with $16-30 \mathrm{w} / \mathrm{w}$ concentration range, at $140{ }^{\circ} \mathrm{C}$ on hot plate for few minutes. The polymeric solution is then loaded in a $1 \mathrm{ml}$ plastic syringe with a 19 gauge stainless steel needle. An electrospinning voltage $(9 \mathrm{kV})$ is applied to the needle using a high voltage power supply (EL60R0.6-22, Glassman High Voltage Inc.). The injection flow rate is kept constant at $10 \mu 1 \mathrm{~min}^{-1}$, supplied by a microfluidic pump (Harvard Apparatus). The fibers are collected on round borosilicate glass coverslips (diameter $12 \mathrm{~mm}$ ), mounted on a grounded 
$10 \times 10 \mathrm{~cm}^{2}$ collector on an insulating stand, at a distance of $9 \mathrm{~cm}$ from the needle. The air humidity and temperature conditions are about $50 \%$ and $23{ }^{\circ} \mathrm{C}$, respectively. The fibers are stored under vacuum at room temperature.

\section{Protein coating}

Before collagen immobilisation, oxygen plasma is performed by a tabletop system (Tucano, Gambetti Kenologia) at $30 \mathrm{~W}$ for 5 min. Fiber samples without plasma treatment are also studied as a reference. The collagen powder is dissolved in $0.1 \mathrm{M}$ acetic acid to realise a $1 \mathrm{mg} \mathrm{ml}^{-1}$ solution, and shaken overnight at $4{ }^{\circ} \mathrm{C}$. The fiber samples for protein coating, after plasma treatment, are divided in four groups and immersed overnight (about $12 \mathrm{~h}$ ) in four different solutions at $4{ }^{\circ} \mathrm{C}$, as schematised in Fig. 2:

(A) a collagen solution, prepared as described (PHY method);

(B) a collagen solution with the addition of $2 \%$ of GA (GA method);

(C) a collagen solution with the addition of $5 \mathrm{mg} \mathrm{ml}^{-1} \mathrm{EDC}$ (EDC-1 method);

(C) ultrapure water solution with $5 \mathrm{mg} \mathrm{ml}^{-1} \mathrm{EDC}$ (for $4 \mathrm{~h}$ at $4{ }^{\circ} \mathrm{C}$ ), then washed with ultrapure water and immersed in collagen solution (EDC-2 method).

All the investigated functionalisation approaches are reported as optimised binding methods for protein immobilisation on surfaces. ${ }^{10,11,36-40}$ Samples are then washed twice with abundant ultrapure water, shaken for $30 \mathrm{~min}$ to remove any unbound protein and residual linker molecules, dried at room temperature with a nitrogen flux and stored at $4{ }^{\circ} \mathrm{C}$. GA-treated samples are incubated in $100 \mathrm{mM}$ aqueous glycine solution at $4{ }^{\circ} \mathrm{C}$ for $2 \mathrm{~h}$ to block the residual aldehyde groups of GA, and washed twice again before storage.

\section{Static contact angle measurements}

Sessile drop contact angle measurements are carried out by $2 \mu \mathrm{l}$ ultrapure water drops, gently delivered from a capillary tip onto the fibers surfaces. The water static contact angles are measured using an Optical Video Contact Angle System CAM-200 KSV (KSV Instruments). Reference PMMA films for contact angle measurements are spin-cast on borosilicate glass coverslips from the same electrospinning solution $(26 \% \mathrm{w} / \mathrm{w}$ in formic acid), at $4000 \mathrm{rpm}$ for $60 \mathrm{~s}$.

\section{SEM analysis}

For SEM investigation, fibers are coated by a $8 \mathrm{~nm}$ Au layer by thermal evaporation (PVD75, Kurt J. Lesker Co.) and then imaged by a Raith 150 system using an accelerating voltage of $5 \mathrm{kV}$ and an aperture size of $20 \mu \mathrm{m}$. The average diameter of the fibers are calculated from the SEM micrographs by standard image analysis. ${ }^{45}$

\section{HATR-FTIR spectroscopy and CLSM investigation}

The fibers before and after functionalisation are analysed by HATR-FTIR spectroscopy (Spectrum 100, Perkin Elmer Inc.), with $2 \mathrm{~cm}^{-1}$ resolution, utilising a $\mathrm{ZnSe} 45$-degree flat-plate. Spectra are baseline-corrected and smoothed. FITC-labelled type I collagen is used to functionalise fibers and investigate the protein distribution by CLSM. The samples are inspected by an Olympus FV-1000 microscope equipped with a $40 \times$ objective and an Ar laser source (excitation wavelength $488 \mathrm{~nm}$; VFC SP 2009, CVI Melles Griot). PMMA fibers without functionalisation are used as negative control.

\section{Collagen quantification assay}

A BCA kit is used to investigate the amount of adsorbed proteins. The samples are incubated in $1 \mathrm{ml}$ of BCA working reagent, for $30 \mathrm{~min}$ at $37^{\circ} \mathrm{C}$. The absorbance at $562 \mathrm{~nm}$ is then measured by a spectrophotometer (Lambda 950, Perkin Elmer Inc.). As reference for coated collagen, a 12 points standard curve in duplicate is calculated using collagen solutions. Each quantification measurement is repeated on at least ten normally identical samples.

\section{Cell culture and proliferation assay}

Fibers samples are first immersed in PBS. An UV treatment (sample distance of $40 \mathrm{~cm}$ from a $8 \mathrm{~W}$ lamp, G30T8, Sankyo Denki) in a laminar flow hood is used to sterilise samples before cell cultures, as reported for both PMMA biomaterials and protein-functionalised fibers. ${ }^{11,46}$ A short time $(1 \mathrm{~h})$ is used for the UV treatment to not significantly degrade collagen structures, as established. ${ }^{47}$ Both as-produced fibers and plasma treated samples are evaluated as negative controls in cell culture experiments. HK-2 cells are grown in DMEM/F12 medium, supplemented with $5 \%$ heat inactivated FBS, $100 \mathrm{U} / \mathrm{ml}$ penicillin, and $0.1 \mathrm{mg} \mathrm{ml}{ }^{-1}$ streptomycin, at $37{ }^{\circ} \mathrm{C}$ under a humidified atmosphere of $5 \% \mathrm{CO}_{2} / 95 \%$ air, as reported. ${ }^{48}$ For passage, the medium is discarded, confluent cells are washed with PBS and removed with a trypsin/EDTA solution. Finally, HK-2 cells are starved on PMMA scaffolds and tissue culture plate (TCPcontrol) in 24-well plates, at a concentration of $4 \times 10^{4}$ cells ml ${ }^{-1}$, replacing the culture medium at each 3 days. The cell growth is carefully monitored by an inverted optical microscope (Leica DMIL), equipped with phase contrast objectives and a digital camera (Canon Europa NV). The cell proliferation is analyzed after 1, 3, and 5 days by MTS assay. The number of viable cells on different substrates is determined exploiting the conversion of tetrazolium salt in MTS solution to soluble formazan dye by metabolically active cells. At each time point, MTS solution is added to medium in all wells at final $10 \% \mathrm{v} / \mathrm{v}$ concentration. The cells are incubated at $37^{\circ} \mathrm{C}$ for additional three hours and the absorbance is determined at $490 \mathrm{~nm}$ by a spectrophotometer.

\section{Total proteins quantification assay}

A BCA kit is used to investigate the total proteins immobilised on the fibers. The functionalised samples and the negative controls (both as-produced and plasma-treated fibers) are processed analogously to samples for cell cultures, at $37^{\circ} \mathrm{C}$ under a humidified atmosphere of $5 \% \mathrm{CO}_{2} / 95 \%$ air, without cells. At planned times samples are washed twice with ultrapure water, shaken for 30 min and used for BCA assay. Each measurement is repeated on at least ten normally identical samples. 


\section{Statistics}

The fibers diameter, contact angles, BCA and MTS results are expressed as mean \pm standard deviation. SEM morphology measurements are carried out on at least 150 fibers per sample. BCA and MTS assay experiments are performed on ten and eight samples, respectively, for each typology. Differences between two groups are determined using unpaired Student t-test. Values of $\mathrm{P}<0.05$ and $\mathrm{P}<0.01$ are both considered in statistical analysis.

\section{Acknowledgements}

The NNL group acknowledges the support from the Italian Institute of Technology (IIT) and from the Italian Minister of University and Research by the FIRB Contract RBIP068JL9. The BioAgroMed group thanks the European Community's 7th Framework Programme, grant agreement $n^{\circ}$ HEALTH-F52008-223007 STAR-T REK. The authors also thank the Apulia Region Strategical Projects n. 144 and 094.

\section{References}

1 W. T. Liu, J. Biosci. Bioeng., 2006, 102, 1.

2 A. Offenhausser, S. Bocker-Meffert, T. Decker, R. Helpenstein, P. Gasteier, J. Groll, M. Moller, A. Reska, S. Schafer, P. Schultea and A. Vogt-Eisele, Soft Matter, 2007, 3, 290.

3 E. Engel, A. Michiardi, M. Navarro, D. Lacroix and J. A. Planell, Trends Biotechnol., 2008, 26, 39.

4 C. Wingren and C. A. K. Borrebaeck, Drug Discovery Today, 2007, 12, 813 .

5 G. Coward-Kelly and R. R. Chen, Biotechnol. Prog., 2007, 23, 52.

6 R. Lanza, R. Langer and J. Vacanti, Principles of Tissue Engineering, Academic Press, New York, third edn, 2007.

7 D. H. Reneker and I. Chun, Nanotechnology, 1996, 7, 216.

8 K. J. Shields, M. J. Beckman, G. L. Bowlin and J. S. Wayne, Tissue Eng., 2004, 10, 1510.

9 E. D. Boland, J. A. Matthews, K. P. Pawlowski, D. G. Simpson, G. E. Wnek and G. L. Bowlin, Front. Biosci., 2004, 9, 1422.

10 Z. W. Ma, W. He, T. Yong and S. Ramakrishna, Tissue Eng., 2005, $11,1149$.

11 W. S. Li, Y. Guo, H. Wang, D. J. Shi, C. F. Liang, Z. Ye, F. Qing and J. Gong, J. Mater. Sci.: Mater. Med., 2008, 19, 847.

12 W. He, Z. Ma, T. Yong, W. E. Teo and S. Ramakrishna, Biomaterials, 2005, 26, 7606 .

13 J. S. Choi and H. S. Yoo, J. Bioact. Compat. Polym., 2007, 22, 508.

14 T. G. Kim and T. G. Park, Biotechnol. Prog., 2006, 22, 1108.

15 Y. Duan, Z. Wang, W. Yan, S. Wang, S. Zhang and J. Jia, J. Biomater. Sci., Polym. Ed., 2007, 18, 1153.

16 H. S. Koh, T. Yong, C. K. Chan and S. Ramakrishna, Biomaterials, 2008, 29, 3574.

17 F. Ding and H. D. Humes, Nephron Exp. Nephrol., 2008, 109, e118.
18 J. Tumlin, R. Wali, W. Williams, P. Murray, A. J. Tolwani, A. K. Vinnikova, H. M. Szerlip, J. Ye, E. P. Paganini, L. Dworkin, K. W. Finkel, M. A. Kraus and H. D. Humes, J. Am. Soc. Nephrol., 2008, 19, 1034.

19 S. Gross, D. Camozzo, V. Di Noto, L. Armelao and E. Tondello, Eur. Polym. J., 2007, 43, 673.

20 P. J. Lou, W. F. Cheng, Y. C. Chung, C. Y. Cheng, L. H. Chiu and T. H. Young, J. Biomed. Mater. Res., Part A, 2009, 88a, 849.

21 S. Patel, R. G. Thakar, J. Wong, S. D. McLeodd and S. Li, Biomaterials, 2006, 27, 2890.

22 S. Tao, C. Young, S. Redenti, Y. Zhang, H. Klassen, T. Desai and M. J. Young, Lab Chip, 2007, 7, 695.

23 R. A. Osorio, M. Follmer, R. W. Layne, R. P. Boucher, K. D. Talmadge and J. J. Basista, US Pat., 6726 691, 2001.

24 Y. Ito, J. Zheng, Y. Imanishi, K. Yonezawa and M. Kasuga, Proc. Natl. Acad. Sci. U. S. A., 1996, 93, 3598.

25 Y. Bai, C. G. Koh, M. Boreman, Y. J. Juang, I. C. Tang, L. J. Lee and S. T. Yang, Langmuir, 2006, 22, 9458.

26 T. J. Sill and H. A. von Recum, Biomaterials, 2008, 29, 1989.

27 M. J. Ryan, G. Johnson, J. Kirk, S. M. Fuerstenberg, R. A. Zager and B. Torok-Storb, Kidney Int., 1994, 45, 48.

28 M. Li, J. Zhang, H. Zhang, Y. Liu, C. Wang, X. Xu, Y. Tang and B. Yang, Adv. Funct. Mater., 2007, 17, 3650.

29 D. Grafahrend, J. Lleixa Calvet, J. Salber, P. Dalton, M. Moeller and D. Klee, J. Mater. Sci.: Mater. Med., 2008, 19, 1479.

30 B. M. Min, G. Lee, S. H. Kim, Y. S. Nam, T. S. Lee and W. H. Park, Biomaterials, 2004, 25, 1289.

31 H. Dong, V. Nyame, A. MacDiarmid and W. Jones, J. Polym. Sci., Part B: Polym. Phys., 2004, 42, 3934.

32 C. P. Barnes, S. A. Sell, E. D. Boland, D. G. Simpson and G. L. Bowlin, Adv. Drug Delivery Rev., 2007, 59, 1413.

33 C. Oehr, Nucl. Instrum. Methods Phys. Res., Sect. B, 2003, 208, 40.

34 F. Xu, P. Datta, H. Wang, S. Gurung, M. Hashimoto, S. Wei, J. Goettert, R. L. McCarley and S. A. Soper, Anal. Chem., 2007, 79, 9007.

35 J. Chai, F. Lu, B. Li and D. Y. Kwok, Langmuir, 2004, 20, 10919.

36 J. van den Dolder, G. N. Bancroft, V. I. Sikavitsas, P. H. M. Spauwen, A. G. Mikos and J. A. Jansen, Tissue Eng., 2003, 9, 505.

37 Z. Ma, Z. Mao and C. Gao, Colloids Surf., B, 2007, 60, 137.

38 R. A. Williams and H. W. Blanch, Biosens. Bioelectron., 1994, 9, 159.

39 G. T. Hermanson, Bioconjugate Techniques, Academic Press, New York, second edn, 2008.

40 M. Gümüsderelioglu and H. Türkoglu, Biomaterials, 2002, 23, 3927.

41 I. K. Kang, B. K. Kwon, J. H. Lee and H. B. Lee, Biomaterials, 1993, 14, 787.

42 B. B. Doyle, E. G. Bendit and E. R. Blout, Biopolymers, 1975, 14, 937.

43 P. K. Smith, R. I. Krohn, G. T. Hermanson, A. K. Mallia, F. H. Gartner, M. D. Provenzano, E. K. Fujimoto, N. M. Goeke, B. J. Olson and D. C. Klenk, Anal. Biochem., 1985, 150, 76.

44 K. M. Woo, V. J. Chen and P. X. Ma, J. Biomed. Mater. Res., 2003, 67a, 531 .

45 I. Horcas, R. Fernandez, J. M. Gomez-Rodriguez, J. Colchero, J. Gomez-Herrero and A. M. Baro, Rev. Sci. Instrum., 2007, 78, 13705. 46 C. Ozcan and N. Hasirci, J. Biomater. Sci., Polym. Ed., 2007, 18, 759.

47 R. J. Davidson and D. R. Cooper, Biochem. J., 1967, 105, 965.

48 L. Gesualdo, E. Ranieri, R. Monno, M. R. Rossiello, M. Colucci, N. Semeraro, G. Grandaliano and F. P. Schena, Kidney Int., 1999, 56, 461 . 